\title{
Experimental analysis of T-beam reinforced concrete with holes
}

\author{
Hotma Panggabean ${ }^{1}$ and Nicxson Pakpahan ${ }^{2, *}$ \\ ${ }^{1}$ Lecturer of Civil Engineering Master Program USU, J1. Perpustakaan Kampus USU, Medan, Indonesia. \\ ${ }^{2}$ Student of Civil Engineering Master Program USU, Jl. Perpustakaan Kampus USU, Medan, Indonesia.
}

\begin{abstract}
The construction of lanes for the installation of reinforced concrete structures using holes are used for multi-storey buildings, which is required for utility networks such as power lines, piping, telephone cables, air conditioners, etc. The utility networks are usually sited in the space above the ceiling or attached by installation to the beam. Consequently, it can be reduced by the height of the rooms in the buildings and as well as debauched aesthetically. An alternative design is needed, and one of which would be implemented by utilizing spaces on the beam structures. In this research, we used an experimental method by performing analytical calculations initially, then the results from the laboratory were checked for collapse model on the test object I, which is a flexural collapse model. The collapse model on Test objects II and III was a shear failure model. Further, the test specimen III of 3-hollow T-beam cross section was feeblest from the other cross-section, with the type of shear failure occurring on the holes of the maximum shear area.
\end{abstract}

Keywords: Hollow T-beam, Flexural failure, Shear failure.

\section{Introduction}

\subsection{Background}

The construction of lanes for the installation of reinforced concrete structures is carried out by creating holes in the structural parts. This is generally used for the construction of multistorey buildings that require utility networks such as power lines, piping, telephone cable, air conditioning, etc. These networks are usually sited in the space above the ceiling or attached by installation to the beam. Consequently, it can be reduced by the height of the rooms in the buildings as well as debauched aesthetically. An alternative design is needed, and one which would be implemented by utilizing spaces on the beam structures.

When the structures of the building are reinforced to become concrete structures, it makes the design of hollow reinforced concrete beam in the body appropriate. Its function is for the purpose of strengthening the building, as well as providing support for the utilities. Further, the holes in the beam can minimize height or space, thereby reducing the volume of concrete used during construction while also making it look very neat. The

* Corresponding author: Nicxson.pakpahan@gmail.com 
reduction in the cross-sectional dimension of hollow reinforced concrete beams has a direct impact on the strength of the beam structure. Therefore, a reduction in the cross-sectional dimension reduces the strength of the beam. Also, creating holes on the beams can reduce the stiffness of the block. To ensure its stability, the proper analysis is required in order to get the effect of holes on the body of the reinforced concrete beam within its capacity.

\subsection{Purpose}

The purposes of this research are:

- Observe the difference in the ultimate load from the intact concrete cross section with the concrete cross section.

- Observe the patterns of cracks that will occur in concrete blocks and concrete beams.

- Observe the load ratio on 3 specimens as follows:

- Test Material 1: Intact concrete cross section.

- Test Material 2: Concrete cross-section with two (2) sections of holes under load

- Test Material 3: Concrete cross section perforated with holes between loads and pedestals, and in pure bending areas with three (3) sections of holes.

\subsection{Laboratory test method}

The test was carried out on the beam by loading four (4) points of load on one type of cross-section, using three (3) specimens i.e. Test Material 1, intact concrete cross section, Test Material 2, concrete cross-section with two (2) sections of holes under load, and Test Material 3, concrete cross section perforated with holes between loads and pedestals, and in pure bending areas with three (3) sections of holes.

\section{Library studies}

\subsection{Test materials}

Reinforced concrete is a mixture of Portland cement or other hydraulic cement, fine aggregate, coarse aggregate and water, with or without adding materials to create a solid mass, while also having reinforced steel in it. Threaded Steel is used to for reinforced concrete, usually a diameter of $10 \mathrm{~mm}$ and $19 \mathrm{~mm}$.

\subsection{Testing materials model}

Modelling the T-shaped Test Object I, it was observed as shown below. Test Object I have a full-face T-beam as shown in Figure 1.
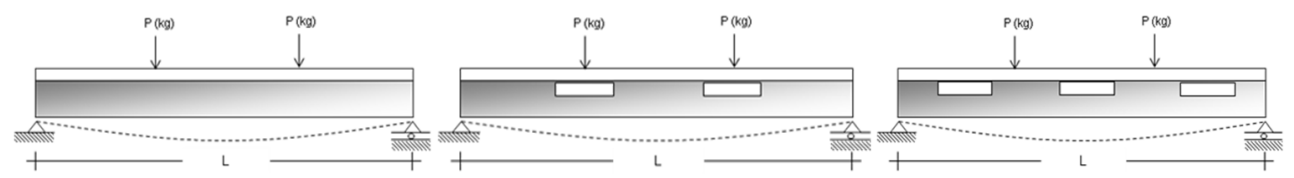

Fig. 1. The modelling of test object I

Test object II has two (2) holes under loads, and Test Item III has three (3) holes.

Dimensions of the T-beam is shown in Figure 2. 


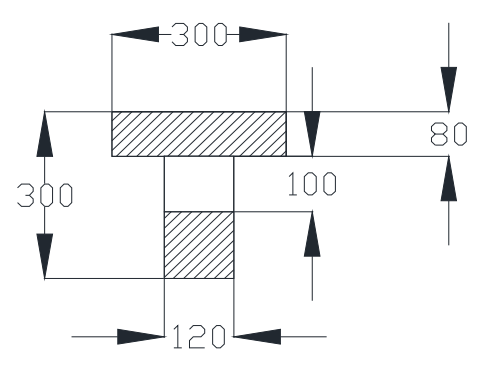

Fig. 2. Dimensions of the T-beam

\subsection{The T-beam theory}

The T-beam that is commonly used has a quadrilateral cross-section. For this reason, the slab/floor used during casting is always fixed together with the beam. It is done by working together with the monolith part of the slab, which reflects the flange of the beam.

According to SNI 2847-2013, the basic principles of rectangle beams design which also applies to beam cross section is as follows:

- In the T-beam construction, the wing and beam bodies must be built up together or at least it must be sealed together effectively.

- The effective slab width of a T-beam wing should not exceed a quarter of the length of the beam span, and the effective width of the wings hanging on each side of the body of the beam should not surpass:

- Eight times the thickness of the slab; and

- Half the net distance of the body next to it.

- For beams with slabs on one side only, the effective width of the hanging wings should not exceed:

- One-twelve the beam length;

- Six times the thickness of the slab; and

- Half the net distance of the body next to it.

- A separate beam, in which the T-shape is used to provide wings for an additional tap area, shall have a wing thickness of not less than half the width of the body and the effective width of the wing must not be more than four times the width of the body.

- If the main resilient bone in the slab considered to be a T-beam wing (excluding the beam construction) is parallel to the beam, the reinforcement perpendicular to the beam shall be provided on the top side of the slab according to the following:

- The transverse strand shall be designed to carry a loaded load on the hanging slab width assumed to work as a cantilever. For separate beams, the entire width of the hanging wing should be taken into account. For other T-blocks, only the effective width of hanging slabs should be taken into account.

- The transverse beam shall be dispensed no farther than five times the thickness of the slab, nor should it exceed $450 \mathrm{~mm}$.

The calculation for T-beam can be divided into several types of cases based on the height of the neutral line as shown in Figure 3.

Case 1. The neutral line height was less than the thickness of the flange.

Case 2. Higher neutral lines over the thick flange. 


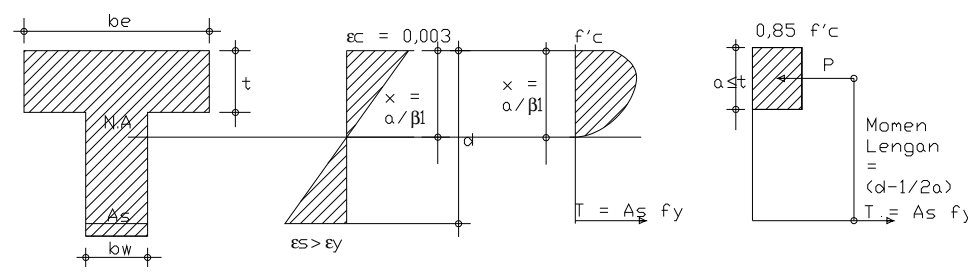

Fig. 3. Stress-strain diagram of T-beam

\subsection{Previous modelling of testing objects}

The previous research regarding reinforced concrete with holes was conducted by Mangantar Silalahi [1,2] in his thesis of Analysis and Assessment Experimental of Reinforced Concrete with Holes. One of the Modelling of Tests objects in his study was observed with the shape of the rectangular concrete beam as presented in Fig 4:

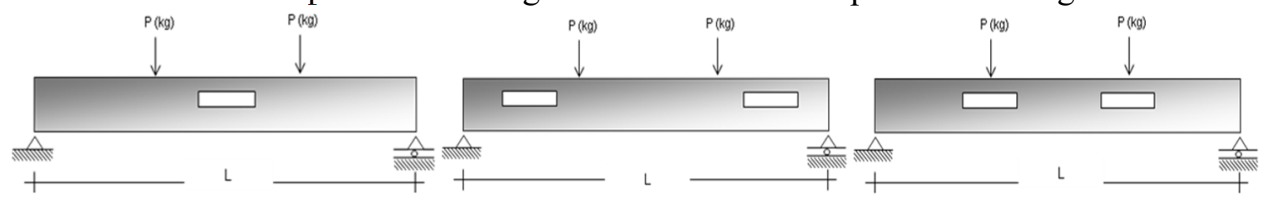

Fig. 4. Modelling of test material I, II and III previous tests

However, the difference between prior researches in comparison to this one is the reliance on holes position and the use of cross-sections. Also, in the previous test, the crosssection used was made in rectangular forms. Meanwhile, in this research, the testing was conducted using the cross-section of the T-beam. Further, holes position in previous studies used holes in the middle by extend two holes between pillars and lots, as well as two holes underneath the pillars. In this research, we used intact cross-section with two holes underneath the pillars and the cross sections, with the three holes between pillars and lots i.e. two holes and one hole in the middle.

\subsection{Theory of balance reinforced concrete beam}

When the number of tensile reinforcements on the concrete cross section causes strain between the steel strain and the balanced concrete strain, it is called balance reinforced concrete beam, and when the pre-requirements are encounter, the value of the concrete strain is obtained, $(\varepsilon c)=0.003$. Hence, the high neutral line formed by the balanced balancing equation is such as follows:

$$
x=\frac{\varepsilon c}{\varepsilon c+\varepsilon s} d
$$

And the equivalent block of the equation is formed by the following equation,

substitution

$$
a=\beta 1 * x
$$

$$
\beta 1=0,85
$$

From the stress-strain block equation, it is formed from equilibrium forces with the condition $\mathrm{T}=\mathrm{P}$ whereas,

$$
P=0,85 f^{\prime} \text { c. be. } a
$$


and

$$
T=A s . f y
$$

\subsection{Theory of under reinforced concrete beam}

When the number of tensile reinforcements at the concrete cross section causes the strain between the steel strain and the concrete strain $<0.003$, it is called weak repeating beam and when the pre-requirements are found, it can be obtained that the value of the concrete strain, $(\varepsilon c)<0.003$. Assuming the T-beam repeating weakly, then it can be examined by the initial assumption of $\varepsilon s=0.005$, and searching for the value of $\varepsilon c$,

$$
c=\frac{\varepsilon c}{\varepsilon c+5} d
$$

By substitution, from the general equation (1) with equation (5), we form the new equations,

$$
\begin{aligned}
& \varepsilon^{\prime} s 1=\frac{(c-d 1)}{c} \varepsilon c \\
& \varepsilon^{\prime} s 2=\frac{(c-d 2)}{c} \varepsilon c
\end{aligned}
$$

If $\varepsilon^{\prime} \mathrm{s} 1>\varepsilon y$, then possibly f's $1=\mathrm{fy}$

If $\varepsilon^{\prime}$ 's $>\varepsilon y$, then possibly f's $2=$ fy

Terms of equilibrium,

$$
D=0,85 . f^{\prime} c . a . b e
$$

The next equation is formed as follows,

$$
z^{\prime} 1=\text { As. } f y
$$

with $z^{\prime} 1$ as the upper layers .1

$$
z^{\prime} 2=\text { As. fy }
$$

with z'2 as the upper reinforcement of layer 2 to form a new equation

$$
Z=D+z^{\prime} 1
$$

Substitution, equation (2.8) and equation (2.11), the new equation is as follows:

$$
\text { As. } f y=\left(0,85 f^{\prime} c \cdot b \cdot \frac{\varepsilon c}{\varepsilon c+5} \cdot d \cdot b e\right)+A^{\prime} s 1 \cdot f y
$$

and when the calculation was obtained, $\varepsilon c<0,003$, the conclusion then would be the beam is under reinforced.

\subsection{Theory of over reinforced concrete beam}

When the number of tensile reinforcements at the concrete cross section causes the strain between the steel strain and the concrete strain $>0.003$, it is called strong repeating beam, and when these conditions are met, the value of the concrete strain, $(\varepsilon c)<0.003$. Assuming that the whole beam repeats are over reinforced, it can be examined by the initial assumption. Assuming the T-beam repeats is strong, hence $\varepsilon c u=0,0035$, and then the value of $\varepsilon s$ is obtained from the following equation;

$$
c=\frac{3.5}{3.5+\varepsilon s} d
$$


By substitution, from equation (11) and equation (13), we obtained the following equation:

$$
\text { As. } f y=\left(0.85 f^{\prime} c \cdot b \cdot \frac{\varepsilon c}{\varepsilon c+5} \cdot d \cdot b e\right)+A^{\prime} s 1 . f y
$$

The substitution of the above equation becomes,

$$
\text { As. } f y-A^{\prime} s 1 . f y=\left(0.85 f^{\prime} c . b . \frac{\varepsilon c}{\varepsilon c+5} . d . b e\right)
$$

and when the calculation is obtained, $\varepsilon c<0,005$, the conclusion would, therefore, be that the beam is over reinforced.

\section{Laboratory testing}

\subsection{Preparation of test materials}

The test materials were prepared and calculated in advance and analysed, it was then made into three (3) test specimens as shown in Figure 4, using Test Material I, Test Material II and Test Material III as shown below.
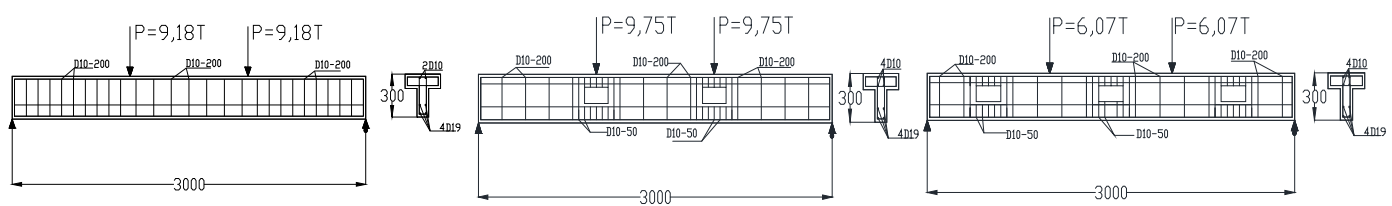

Fig. 5. Test material I, II and III

Material testing was conducted to identify the quality of concrete by using hammer test, and tensile test against iron concrete, this was conducted in the laboratory of State Polytechnic of Medan as shown in Figure 5 and 6 below.
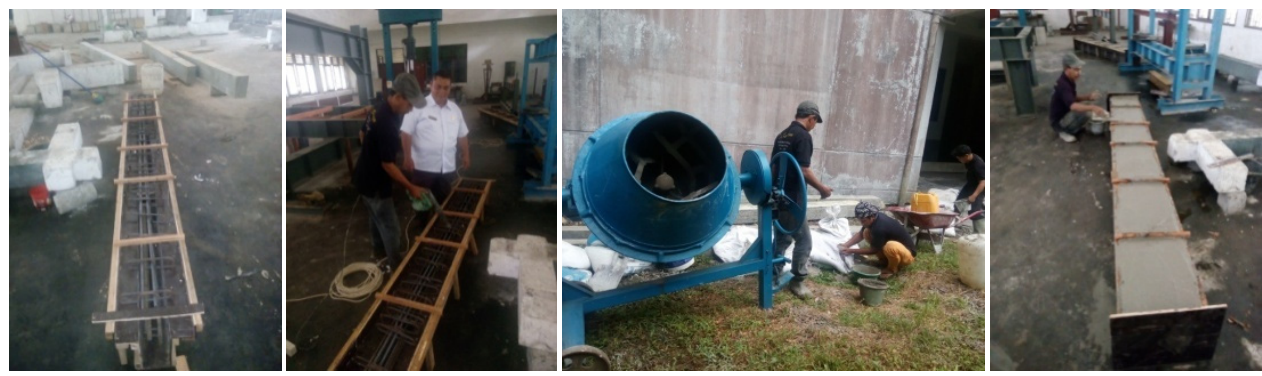

Fig. 6. Creation of test objects
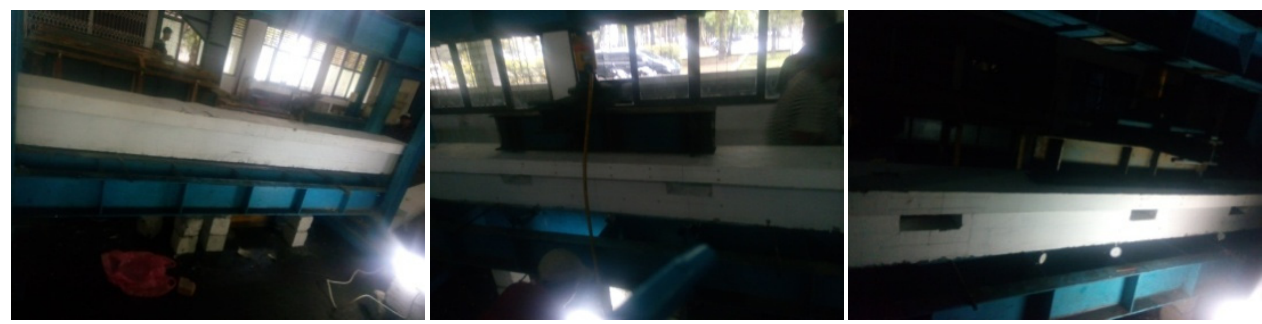

Fig. 7. Test material I, test material II, and test material III 


\section{The results of laboratory test analysis}

\subsection{Compressive strength results with hammer test}

The compressive strength of concrete is tested using the Hammer Test Tools, and the results of the test are presented in Table 1.

Table 1. Compressive strength result on test material

\begin{tabular}{|c|c|}
\hline Type & Compressive Strength \\
\hline Test Material I & K 211 \\
\hline Test Material II & K 216 \\
\hline Test Material III & K 200 \\
\hline
\end{tabular}

\subsection{Ultimate tensile measurement of steel reinforcement}

Strong Testing Pull steel reinforcement was done at the Mechanical Engineering Laboratory of the State Polytechnic of Medan, using two (2) pieces of the samples. The type of materials used was having a diameter of $10 \mathrm{~mm}$ and $19 \mathrm{~mm}$. The test results are presented in Table 2.

Table 2. Ultimate tensile measurements results

\begin{tabular}{|c|c|c|c|c|c|}
\hline Diameter & Fy $(\mathrm{N})$ & Fu $(\mathrm{N})$ & $\sigma \mathrm{y}(\mathrm{MPa})$ & $\sigma \mathrm{u}(\mathrm{MPa})$ & $\varepsilon(\%)$ \\
\hline D 10 & 31.200 & 47.500 & 397.45 & 605.09 & 20.59 \\
\hline D 19 & 32.100 & 47.800 & 499.3 & 743.50 & 18.11 \\
\hline
\end{tabular}

\subsection{Deflection analysis of test results}
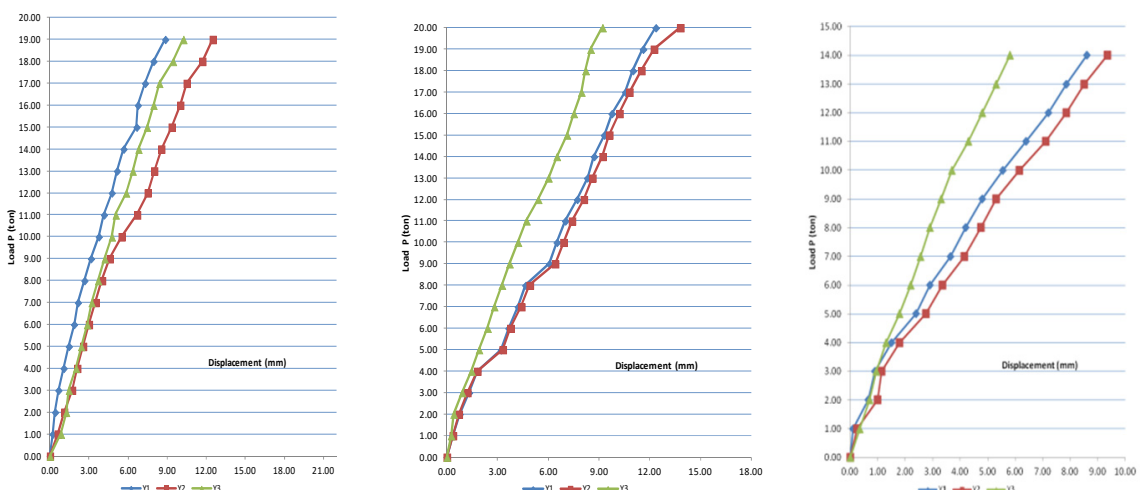

Deflection in the middle of extends Deflection in distance of $\mathrm{L} / 3$ from left side Deflection in distance of $2 \mathrm{~L} / 3$ from the left side.

Fig. 8. Graphs of expense P (ton) and deflection (mm) of test results I, II and III

Tests performed on three (3) specimens are shown in Figure 4.1 above. 
The deflection that occurred as seen in Figure 4.1 shows that on Test Material I, the maximum deflection is $12.5 \mathrm{~mm}$, while on Test Material II, it is $13.8 \mathrm{~mm}$ and on Test Material III, the maximum deflection is $9.35 \mathrm{~mm}$.

\subsection{Stress-strain analysis}

The stress-strain observations on Test Materials I, Test Materials II and Test Items III are as shown in Figure 3, 4, 5, 6,7, and 8.

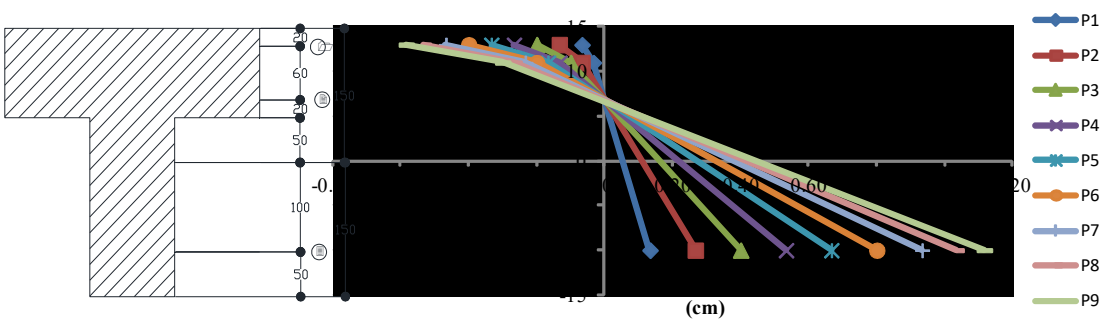

Fig. 9. The stress-strain graph of the left side test object I

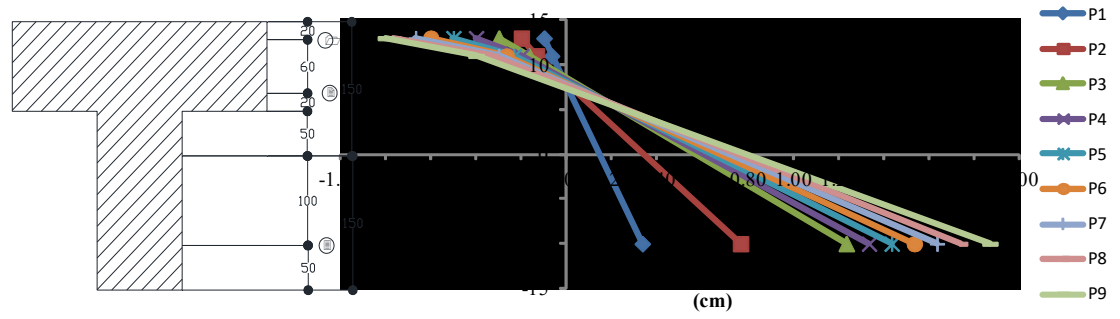

Fig. 10. The stress-strain graph of the middle side test object I

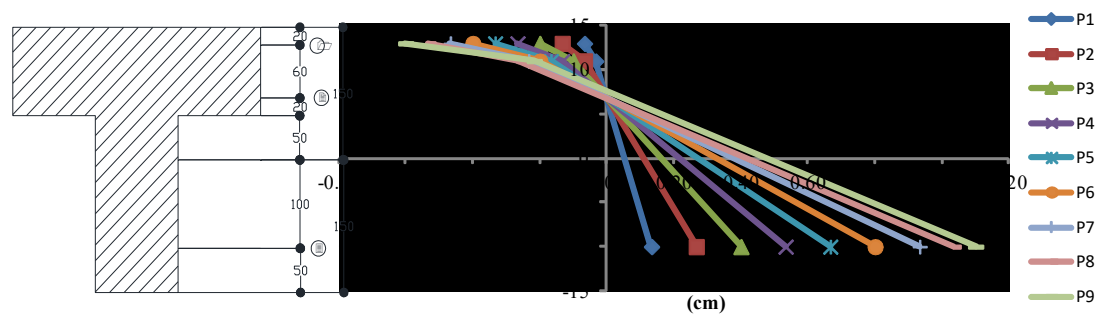

Fig. 11. The stress-strain graph of the left side test object II

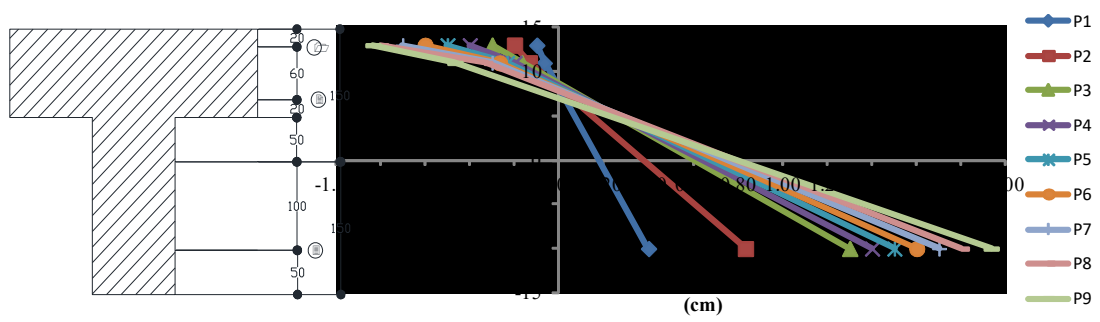

Fig. 12. The stress-strain graph of the middle side test object II 


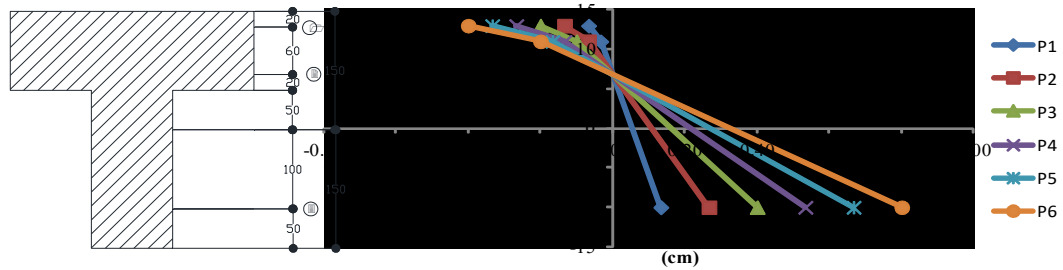

Fig. 13. The stress-strain graph of the left side test object III

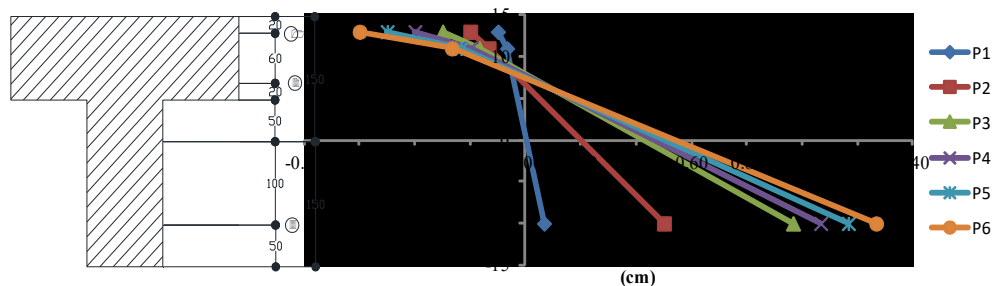

Fig. 14. The stress-strain graph of the middle side test object III

The strain occurring in Figure 3, 4, 5, 6, 7 and 8 show that the maximum strain before collapsing on Test specimen I am $1.87 \% 00,1,93 \%$ for Test specimen II and 1,27\% for Test specimen III.

\subsection{Experimental beam collapse pattern}

The T-beam had collapsed as shown in Figure 14, the collapsed pattern of the Test Object I was as a result of bending that occurs during the collapse [3].
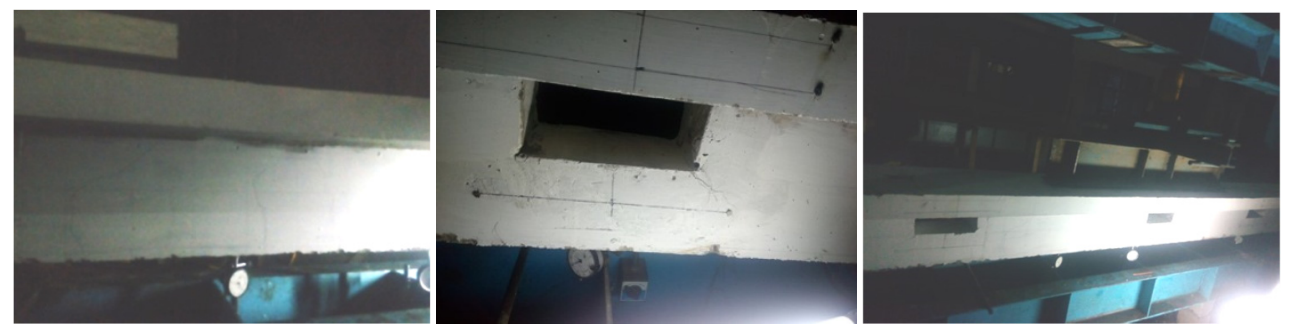

Fig. 15. The beam collapsed and its patterns.

Object II had collapsed as shown in Figure 15, the collapsed pattern of the second test object showed shear failure $[4,5]$, while test object III showed shear collapse pattern.

\section{Conclusions}

After doing the experimental study of the specimens, certain conclusions were made, these are:

1. Load collapsed on the calculations performed on the test object I T-Beam, at the 18.36 Ton mark while in the laboratory when it was subjected to a test of 19 Ton.

2. The load collapsed on the calculations performed on the Test Material II T-beam with two (2) holes, totalling 19.5 Ton, while it was subjected to a test of 20 Ton.

3. Load collapsed on the calculations performed on the Test Material III T-beam with three (3) holes, totalling 12.15 Ton while it was subjected to a test of 14 Ton. 
4. Previous test for Material I, which is a square rectangular beam with one (1) hole in the middle resulted in the collapsed load of 24 Ton.

5. The test Material II which is a square-sectional beam with II (two) holes between load and pedestal in the previous test resulted in a collapsed load of 17 Ton.

6. Testing of Material III on a square cross-section with 2 (two) holes below the load in the previous test resulted in a load of 23.5 Ton.

7. The type of failure of the test specimen I am a type of bending failure that occurs in the pure flexible loading region.

8. The type of failure on test specimen II is a type of shear failure that occurs in holes under a centralized load.

9. The type of failure on test specimen III is a type of shear failure that occurs in the hole in the maximum shear area.

10. The type of failures in Test Material I of the preceding test also showed bending failures, and the failure models in Test Materials II and Third Testing Materials in the previous test showed typical shear failures.

11. The beam elements above the hole were not considered because, by observation, the strain of the beam above the hole was pressed.

Thank you to Dr.Ing. Hotma Panggabean, who was my master study advisor during the research and writing of this article. Special thanks to my friends Valentine Tarigan, Immanuel Panggabean, and Donatus Dahang who had reviewed this paper until it was submitted for publishing.

\section{References}

1. Chris Williams et.al, Strut and Tie Model, Final Report, Texas Department of Transportation, (2012).

2. Silalahi Mangantar, Analisa dan Kajian Experimental Beton Berlubang, Tesis, (2002).

3. Yacob Yonadab Manuhua et al, Analisis Kapasitas Balok Beton Bertulang dengan Lubang pada Badan Balok, Jurnal Sipil Statik Vol.3 No.7 Juli (2015).

4. Kasmat Saleh Nur, Analisis Geser Balok-T Beton Bertulang Berlubang Memanjang dengan Menggunakan Metode Elemen Hingga Non-Linier, Jurnal INERSIA, Vol. VI No. 2, Desember (2010).

5. W.A. Krasna et al, Perilaku Geser pada Keadaan Layan dan Batas Balok Beton Bertulang Berlubang Memanjang, Jurnal Ilmiah Semesta Teknika, Vol. 13, No. 2, 145 154, November (2010). 